\section{Industry in academia: ethical frameworks would clarify links}

The appointment of William Chin, from the drug giant Eli Lilly, as executive dean for research at Harvard Medical School should be judged by the extent to which he can supplant his allegiance to industry and promote the university's mission of social good. Academia cannot be a "pristine bubble" striving to be "untainted and uninformed" by industry, as some critics may have implied (Nature 463, 999-1000; 2010). But universities may, nevertheless, choose to avoid industry funding and not grant academic positions to scientists employed or contracted by outside agencies for activities that could be (mis)construed as scholarly research.

Some researchers advocate standardizing rules for university-industry partnerships; others maintain that their success depends on stringent oversight by independent review panels. But universities should still be prepared to engage with community or industry counterparts. Academics can cooperate with all sectors as equals, beholden neither financially nor politically.

However, it is not always easy to stave off external influences on scholarly integrity. For example, researchers' careers may be put in jeopardy if their industry funding source dislikes their findings. If funding is then withdrawn, they cannot always count on support from their universities.

Universities need to ensure that a proper ethical framework is in place before pursuing commercial partnerships. It is important for public trust, particularly in clinical research, that they adhere to standards of accountability and access to data, as well as taking action against transgressions. To help define, promote and enforce policies that ensure academic freedom and social responsibility in research, universities should establish independent offices for ethical application of innovation and for partnership engagement. Annalee Yassi Global Health Research Program,

Shafik Dharamsi Centre for International Health, Jerry Spiegel Global Health Research Program, University of British Columbia, Vancouver, British Columbia V6T1Z3, Canada

e-mail: ayassi@interchange.ubc.ca

\section{Industry in academia: transparency alone is not enough}

I disagree with your Editorial supporting ties between drug companies and academia (Nature 463, 999-1000; 2010) particularly the appointments of a top Eli Lilly executive as executive dean for research at Harvard Medical School and Genentech's head of product development as chancellor of the University of California at San Francisco.

As a former researcher (PhD in physics from the University of California, Berkeley), I don't consider it is enough that links between industry and academia should be transparent. They need to be kept at a level where the ones with the money can't control those who take the money. It is the public that pays for most research, and we don't want the industry tail to wag the research dog.

Having academic researchers collaborate with a drug company to help turn research into a drug is one thing. But giving former drugcompany executives authority over research is quite different.

It is debatable what these executives bring to academia. Everyone in science knows that, when technical information is being discussed, it is the graduate students and postdocs who are in the room, not the professors, let alone the deans or the administrators.

Theodore Lawry Croydon, Surrey CRO 2PF, UK e-mail: ted_lawry@yahoo.com

\section{Structural changes to aid science in developing countries}

I am quoted in a News story as saying that I wouldn't work in a developing nation again, after having been forced to leave my laboratory at the federal Institute for Scientific and Technological Research of San Luis Potosí in Mexico (Nature 464, 148-149; 2010). Because I have many valued friends and collaborators in developing countries, I would like to clarify this statement, in case it should cause offence.

My brother and I returned to Mexico after doing our doctorates and postdoctoral work abroad, with a view to establishing a firstclass laboratory. We showed unequivocally that working in a developing nation is no bar to doing excellent science. Our students from Mexico's first graduate programme in nanotechnology have excelled. Our key strategy was to work as a team with an innovative horizontal philosophy that involved people from different areas of research in various countries.

Such multinational collaborations are crucial to the success of science, technology and innovation in developing nations. This in turn will help to fight poverty and social problems by improving the quality of life of their inhabitants.

My statement was therefore not intended as an adverse reflection on science in developing nations. Establishing world-class nanotechnology in Mexico called for an incredible amount of effort and personal sacrifice. My declaration was to do with this, indicating only that I would be reluctant at this point in my career to start again from scratch on such a colossal undertaking.

As a scientist, I shall continue to help developing nations, including Mexico, to boost their talented researchers in nanotechnology. But structural changes in the operation of science, its leadership and working philosophy will be necessary, as well as proper teamwork and a promotion system for promising young scientists. Mauricio Terrones Departamento de Ciencia e Ingeniería de Materiales e Ingeniería Química, Universidad Carlos III de Madrid, 28911 Leganés, Spain e-mail:mtterrones@gmail.com

\section{European routes to reinventing Internet technology}

Your News Feature about reinventing Internet technology is timely (Nature 463, 602-604; 2010). Complementary initiatives to the US projects are under way in Europe.

The European initiatives are geared to improving informationsharing over the Internet by radically changing network operation. Content storage will be a core service across applications - unlike in traditional networking, which treats storage as an application property. The new focus will decouple global publishing and consuming from local actions of sending and receiving between network nodes.

Social networking can optimize the Internet for purposes other than security. The rise of mobilephone-based networking makes the handset a primary device for securely locating an individual. Combining knowledge of users' interests and locations will allow us to track demand for multimedia and optimize delivery of content, as well as to predict areas of demand and minimize energy usage. It will be important to guard user privacy while doing so.

At present, only a single path is enabled between two end points at any time for Internet users. This restriction can be lifted for devices with two or more networks, such as mobile phones with both WiFi and 3G. These will mitigate temporary problems with either network and help to balance Internet traffic.

Jon Crowcroft, Eiko Yoneki Computer Laboratory, University of Cambridge, Cambridge CB3 OFD, UK e-mail: jon.crowcroft@cl.cam.ac.uk 